\title{
SARS-CoV-2 Ultraviolet Radiation Dose-Response Behavior
}

\author{
Ernest R. Blatchley III ${ }^{1,2}$, Brian Petri ${ }^{3}$, and Wenjun Sun ${ }^{4}$ \\ ${ }^{1}$ Lyles School of Civil Engineering, Purdue University, \\ West Lafayette, IN 47907, USA \\ ${ }^{2}$ Environmental and Ecological Engineering, Purdue University, \\ West Lafayette, IN 47907, USA \\ ${ }^{3}$ Trojan Technologies, \\ London, Ontario N5V 4T7, Canada \\ ${ }^{4}$ School of Environment, Tsinghua University, \\ Beijing 100084, China \\ blatch@purdue.edu \\ bpetri@trojanuv.com \\ wsun@tsinghua.edu.cn
}

Ultraviolet (UV) radiation in the wavelength range $200 \mathrm{~nm} \leq \lambda \leq 320 \mathrm{~nm}$, which includes both the UV-C and UV-B portions of the spectrum, is known to be effective for inactivation of a wide range of microbial pathogens, including viruses. Previous research has indicated UV-C radiation to be effective for inactivation of severe acute respiratory syndrome coronavirus (SARS-CoV), the virus that caused an outbreak of SARS in 2003. Given the structural similarities of SARS-CoV and SARS-CoV-2, the cause of coronavirus disease 2019 (COVID-19), it is anticipated that UV radiation should be effective for inactivation of SARS-CoV-2 too. Recently published data support this assertion, but only for a narrow set of exposure and matrix conditions. Models based on genomic and other characteristics of viruses have been developed to provide predictions of viral inactivation responses to UV exposure at $\lambda=254 \mathrm{~nm}$. The predictions of these models are consistent with reported measurements of viral inactivation, including for SARS-CoV-2. As such, current information indicates that UV-C irradiation should be effective for control of SARS-CoV-2, as well as for control of other coronaviruses; however, additional research is needed to quantify the effects of several important process variables, including the wavelength of radiation, the effects of relative humidity on airborne and surface-associated viruses, and the effects of the medium of exposure.

Key words: COVID-19; disinfection; SARS-CoV-2; ultraviolet radiation; virus.

Accepted: February 19, 2021

Published: August 20, 2021

This article was sponsored by Dianne L. Poster, Material Measurement Laboratory, and C. Cameron Miller, Physical Measurement Laboratory, National Institute of Standards and Technology (NIST). It is published in collaboration with the International Ultraviolet Association as a complement to the NIST Workshop on Ultraviolet Disinfection Technologies, 14-15 January 2020, Gaithersburg, MD. The views expressed represent those of the authors and not necessarily those of NIST.

https://doi.org/10.6028/jres.126.018 


\section{Introduction}

Ultraviolet (UV) radiation is a broad-spectrum antimicrobial/antiviral agent that has been applied successfully in a wide range of disinfection applications. UV radiation in the wavelength range $200 \mathrm{~nm} \leq \lambda$ $\leq 320 \mathrm{~nm}$, sometimes referred to as "germicidal" or "microbicidal" UV radiation, is known to cause damage to DNA and RNA that results in inactivation of microorganisms and viruses. For radiation with wavelengths less than about $240 \mathrm{~nm}$, damage to proteins can also contribute to inactivation [1-3]. Given that all viruses contain a nucleic acid molecule, either DNA or RNA, and a protein coat (capsid) that surrounds the nucleic acid, all viruses are susceptible to inactivation by exposure to UV-C radiation. However, viral sensitivity to UV-C radiation is quite variable; the development of a comprehensive understanding of the causative factors is still an active area of research.

Severe acute respiratory syndrome coronavirus 2 (SARS-CoV-2; also known as the novel coronavirus) is the virus that causes coronavirus disease 2019 (COVID-19). Transmission of COVID-19 appears to be largely associated with airborne particles that may be released by symptomatic or asymptomatic individuals who have been infected by SARS-CoV-2, although it is also known that the virus can remain infective on surfaces for as much as 24-72 h, depending on the material it is contact with [4], so contact with contaminated surfaces (fomites) represents another possible mechanism of disease transmission [5].

At present, only limited data are available to define how SARS-CoV-2 responds to common disinfectants, including UV radiation. UV dose-response behavior describes the intrinsic kinetics of UV inactivation, and as such, it represents a key piece of information for the design of UV disinfection systems that are intended for inactivation of SARS-CoV-2. The goal of this paper is to present a summary of information that was available at the time of publication to describe inactivation of SARS-CoV-2 by exposure to germicidal UV radiation.

\section{Dose-Response Data for Coronaviruses}

Most UV dose-response experiments have involved exposure of the target microbe or virus to UV radiation while suspended in an aqueous medium. These experiments tend to be relatively easy to conduct and analyze. Moreover, the data from these experiments can be used to inform the design and analysis of UV disinfection systems that are used in treatment of water, which historically have been the most common applications of UV disinfection processes.

The simplest and most commonly applied model to describe UV dose-response behavior (i.e., UV disinfection kinetics) of microbes and viruses is the single-event model, which implies that a single unit of photochemical damage is sufficient to inactivate a microbial or viral target. The single-event model, which implies first-order kinetics, takes the following mathematical form:

$$
\frac{d N}{d t}=-k E N
$$

where $N=$ concentration of viable or infective microbe or virus, $t=$ time, $k=1^{\text {st }}$-order inactivation constant, and $E=$ fluence rate. Separation of variables and integration yields a common form:

$$
\ln \left(\frac{N}{N_{0}}\right)=-k D
$$

where $N_{0}=$ concentration of viable or infective microbes or viruses before exposure to $\mathrm{UV}$ radiation and $D$ $=\mathrm{UV}$ dose, which may also be represented as the product of fluence rate and exposure time. Dose is often 
expressed in units of $\mathrm{mJ} / \mathrm{cm}^{2}$, while the inactivation constant will have units that are the inverse of those used to quantify dose, $\mathrm{cm}^{2} / \mathrm{mJ}$.

Until recently, no data were available to describe the responses of SARS-CoV-2 to germicidal UV radiation. However, several studies that were performed prior to the start of the COVID-19 pandemic reported UV dose-response behavior of SARS-CoV; this is the virus that caused an epidemic of severe acute respiratory syndrome (SARS) that affected roughly 8000 people in 26 countries in 2003 [6]. SARS$\mathrm{CoV}$ is closely related to SARS-CoV-2, with both viruses belonging to the coronavirus family. SARS-CoV and SARS-CoV-2 are both enveloped, single-stranded (ss), positive-sense RNA viruses, and they share roughly $80 \%$ similarity in terms of their genomes [7, 8].

SARS-CoV-2 belongs to the Coronaviridae family, which includes the largest known ssRNA viruses [9]. Coronaviruses $(\mathrm{CoV})$ range in size from 118 to $140 \mathrm{~nm}$, with genome size of 25-32 kilobases $(\mathrm{kb})$. Seven coronaviruses are known to cause disease in humans. These include four viruses that cause the "common cold" (HCoV-229E, HCoV-NL63, HCoV-OC43, and HCoV-HKU1) [10, 11]. Three coronaviruses have been identified that cause more serious, sometimes fatal diseases in humans: SARSCoV, MERS-CoV (cause of Middle East respiratory syndrome, MERS), and SARS-CoV-2. The structural similarity of these viruses, including their relatively large genomes, suggests that they should all be susceptible to inactivation by exposure to UV-C radiation and that their UV-C dose-response behaviors should be similar [10-15].

Studies of the responses of SARS-CoV published to date have been based on UV-C radiation at or near the wavelength $254 \mathrm{~nm}\left(\mathrm{UV}_{254}\right)$, which characterizes the output of low-pressure mercury lamps, which are the most commonly used source of germicidal UV radiation [16-18]. A wide range of responses was reported among the studies, and all had deficiencies in their experimental methods. The reported fluences (doses) were probably overestimates, as UV absorbance of the suspensions was not reported or explicitly accounted for in the experiments. Similarly, the methods used to irradiate the viral suspensions suggest that the UV dose applied could not be accurately calculated. Specifically, in each of these studies, radiation was delivered from a UV-C source in a manner that did not allow for accurate measurement of the applied fluence rate by conventional methods, such as radiometry. Although the results of these studies do not appear to provide accurate information regarding the $\mathrm{UV}_{254}$ dose-response behavior of SARS-CoV, all three studies reported measurable inactivation of the virus to result from $\mathrm{UV}_{254}$ irradiation.

Gerchman et al. [19] conducted a set of experiments to define the dose-response behavior of HCoVOC43 to radiation from various UV light-emitting diodes (LEDs). Specifically, they used UV LEDs with peak output at nominally $267 \mathrm{~nm}, 279 \mathrm{~nm}, 286 \mathrm{~nm}$, and $297 \mathrm{~nm}$, with full-width at half-maximum (FWHM) bandwidths of roughly $12-20 \mathrm{~nm}$. Their experimental design, which involved methods of exposure and dose calculation that were new and somewhat unconventional, resulted in a limit of quantification of $3 \log _{10}$ units of inactivation of the target virus. ${ }^{1}$ Regression of their data that were within the limit of quantification using a single-hit (first-order) model of disinfection kinetics allowed estimation of inactivation constants for HCoV-OC43 as a function of wavelength. These estimates of wavelengthdependent inactivation behavior are summarized in Table 1. Because the genome for HCoV-OC43 is similar in size to that of SARS-CoV-2, and because they are both betacoronaviruses in the Coronaviridae family, it is anticipated that their responses to UV-C radiation will be similar. As such, HCoV-OC43 appears to represent a good surrogate for SARS-CoV-2.

${ }^{1} 3 \log _{10}$ units refers to a $99.9 \%$ reduction, calculated as $\log _{10}\left(N_{0} / N\right)$, where $N_{0}$ is the initial value, and $N$ is the final value. 
Table 1. Estimates of first-order UV inactivation constants for HCoV-OC43 from data reported by Gerchman et al. [19]. Estimates of inactivation constants were developed by regression of data that were within the limit of quantification using a single-hit (first-order) model.

\begin{tabular}{cc}
\hline \hline Wavelength $(\mathrm{nm})$ & Inactivation Constant $\left(\mathrm{cm}^{2} / \mathrm{mJ}\right)$ \\
\hline 267 & 0.77 \\
279 & 0.64 \\
286 & 0.43 \\
297 & 0.14 \\
\hline \hline
\end{tabular}

Since the start of the COVID-19 pandemic, several research groups have undertaken efforts to quantify the UV-C dose-response behavior of SARS-CoV-2. To date, the results of these efforts have appeared in a wide range of publications, including commercial advertisements, press releases, prepublications, and the refereed literature. Figure 1 provides a summary of data from peer-reviewed papers in which it was possible to define, in quantitative terms, the inactivation response of SARS-CoV-2 as a function of applied UV-C dose. However, even in these papers, there remains some ambiguity as to how UV radiation was delivered to the viral targets and how the reported doses were calculated. As with the SARS-CoV work, there was a wide range of responses; data from studies that were judged to indicate likely false-high resistance [20] were excluded from Fig. 1.

Note that in Fig. 1, three of the data sets indicate inactivation responses for the virus suspended in an aqueous medium, while the other two data sets indicate responses of the virus after being applied to a surface as an aqueous suspension and then allowed time to air dry before UV-C exposure. Note also that three of the investigations were conducted using low-pressure Hg lamps as the source of radiation ( $\lambda=$ $254 \mathrm{~nm}$ ), while one investigation was based on UV LED (peak $\lambda=280 \mathrm{~nm}$ ), and another was based on a Krypton Chloride excimer $\left(\mathrm{KrCl}^{*}\right)$ lamp as the source of radiation (peak $\lambda=222 \mathrm{~nm}$ ). Collectively, the data presented in these recent papers indicate that SARS-CoV-2 is quite sensitive to germicidal UV radiation, which is consistent with the behavior of related viruses and the known structure of SARS-CoV-2.

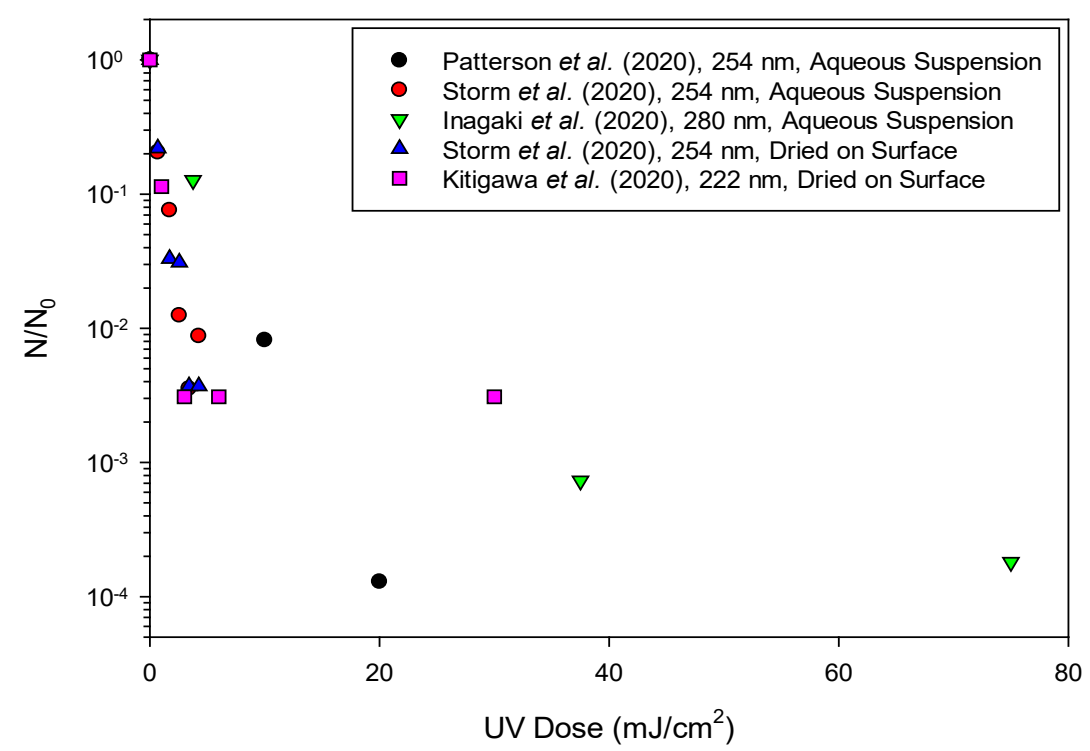

Fig. 1. Reported UV dose-response data for SARS-CoV-2 in aqueous suspension and dried on surfaces [21-24]. $N$ is the final value; $N_{0}$ is the initial value; $3 \log _{10}$ units of inactivation is represented by $10^{-3}$. Note that results are reported for several different wavelengths of UV-C radiation. The nominal wavelength of imposed radiation and the conditions of virus exposure to UV-C radiation are indicated in the legend. The data reported for $254 \mathrm{~nm}$ are all from experiments that involved the use of low-pressure Hg lamps as the source of radiation, with effectively monochromatic output at $254 \mathrm{~nm}$. The data reported for $280 \mathrm{~nm}$ are based on exposure to radiation from a UV LED with peak output at that wavelength. The data reported for $222 \mathrm{~nm}$ are based on exposure to radiation from a $\mathrm{KrCl}^{*}$ lamp with an optical filter used to eliminate all radiation except the dominant peak near $222 \mathrm{~nm}$. 


\section{Action Spectra}

The effectiveness of UV-C radiation as a disinfectant is influenced by the wavelength of radiation. This behavior has become increasingly important in recent years with the development of alternatives to conventional low-pressure mercury lamps, including medium-pressure mercury lamps, UV LEDs, and plasma (excimer) lamps, all of which are polychromatic and have output that varies substantially from $254 \mathrm{~nm}$. The wavelengths of radiation produced by LEDs and excimers depend on their chemical composition. Collectively, these alternative sources provide access to radiation from across the germicidal UV spectrum.

A common graphical method for describing the effects of wavelength on microbial inactivation is the so-called "action spectrum." In most cases, the action spectrum illustrates the relative rate of inactivation of a microbe at a given wavelength compared to its inactivation rate in response to irradiation at $254 \mathrm{~nm}$. An example of a normalized action spectrum for coliphage MS2 in aqueous suspension is presented in Fig. 2. As with most action spectra, the information presented in Fig. 2 indicates that for wavelengths in the range $240 \mathrm{~nm}$ to $300 \mathrm{~nm}$, peak inactivation efficiency is obtained at about $265 \mathrm{~nm}$, with steady decreases at wavelengths above and below this peak. In this wavelength range, the majority of viral inactivation is attributable to photochemical damage to its nucleic acid. For radiation at wavelengths less than about $240 \mathrm{~nm}$, a rapid increase in the efficiency of inactivation occurs; this is attributable to damage to proteins, which is known to take place at these short wavelengths. Damage to nucleic acids also takes place at these relatively short wavelengths, so viral inactivation in this range is attributable to the combined effects of damage to nucleic acids and proteins. It is expected that SARS-CoV-2 will display similar trends, but insufficient data are available at present to confirm or refute this hypothesis.

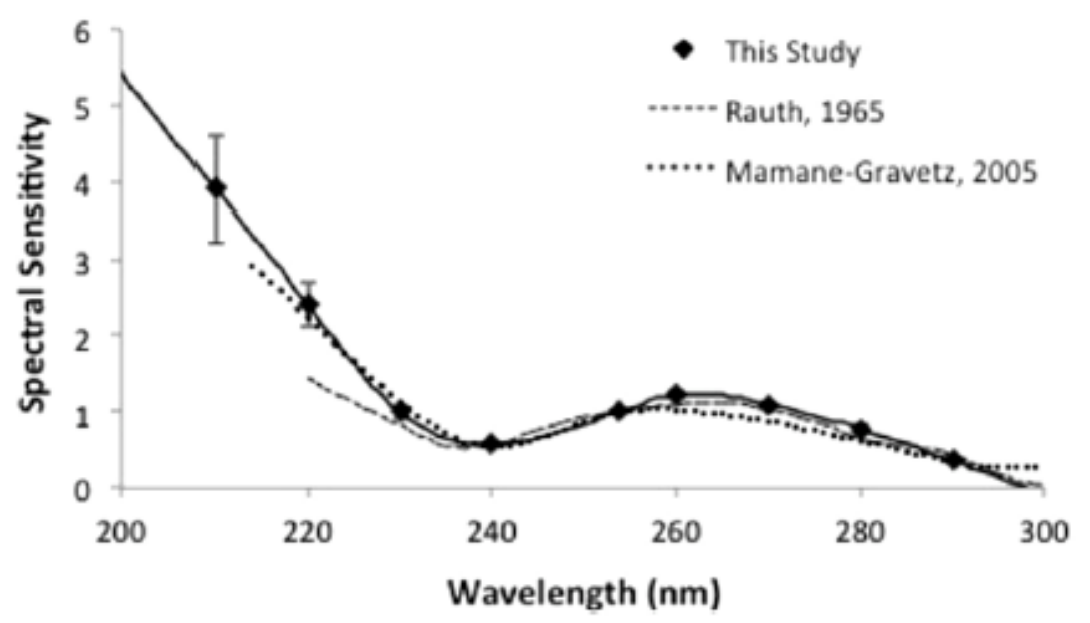

Fig. 2. Normalized action spectrum for coliphage MS2 (figure from Beck et al. [25], indicated as "This Study"; figure reprinted with permission). For all three data sets presented in this graph, the data were normalized against the measured response at $254 \mathrm{~nm}$. Also included in this figure are action spectra from Rauth [26] and Mamane-Gravetz [27]. Error bars represent one standard deviation from the mean sensitivity value; $n=4$ for $240 \mathrm{~nm}, 253.7 \mathrm{~nm}, 260 \mathrm{~nm}$, and $270 \mathrm{~nm}$, and $n=3$ for all other wavelengths tested.

The ultimate disinfection efficacy in an actual application will also be influenced by the absorbance characteristics of the medium that is being disinfected. In some settings, there could be substances that absorb strongly at wavelengths below $240 \mathrm{~nm}$, which will mitigate the contributions of short-wavelength UV-C radiation.

At present, no information is available to define the action spectrum of SARS-CoV-2. Development of an action spectrum for this virus will represent an important contribution to the effort to control the virus, especially in indoor settings. This information is needed to provide a quantitative description of the 
response of SARS-CoV-2 to radiation from the wide range of UV-C sources that are available today. The data from the work of Gerchman et al. [19] will be useful in evaluating the action spectrum of coronaviruses in general and should serve as a guide for future experiments designed to develop an action spectrum for SARS-CoV-2, at least for wavelengths above $267 \mathrm{~nm}$.

\section{Effects of the Medium}

Most UV dose-response data have been reported for experiments wherein the target virus was suspended in water. These experiments are critical for UV disinfection of water; however, the transmission of SARS-CoV-2 (and many other viruses) generally involves aerosolized viruses that are suspended in air or attached to surfaces. For both conditions, the virus may experience drying (desiccation). Desiccation, which will result from exposure to air and will be influenced by relative humidity (RH), is known to represent a form of stress for most microbes and viruses, and it may alter their sensitivity to other forms of environmental stress, including UV-C exposure, as illustrated in Fig. 3 for coliphage MS2 [28-32]. Similar trends have been reported for other aerosolized viruses, including vaccinia virus and influenza H1N1 virus $[33,34]$. However, it should be noted that the effects of RH on coronaviruses and other airborne or surfaceassociated viral pathogens remain somewhat unclear, in that some studies have indicated that these viruses survive longer at low RH [35-37], while others indicate that they survive longer at high RH [38], and still others indicate a non-monotonic association between virus survival and RH [39] or no correlation at all [40]. As such, the effects of RH on airborne viruses and viruses on surfaces, including SARS-CoV-2, represent a subject for continued research.

Other features included in Fig. 3 are the limits for MS2 inactivation suggested by the National Water Research Institute [41]. These limits provide an indication of the variability that can be expected for reported values of viral (or microbial) UV-C dose-response behavior, even for experiments that conform to all relevant experimental protocols. As such, it may be reasonable to expect similar variability to emerge in SARS-CoV-2 UV-C dose-response data.

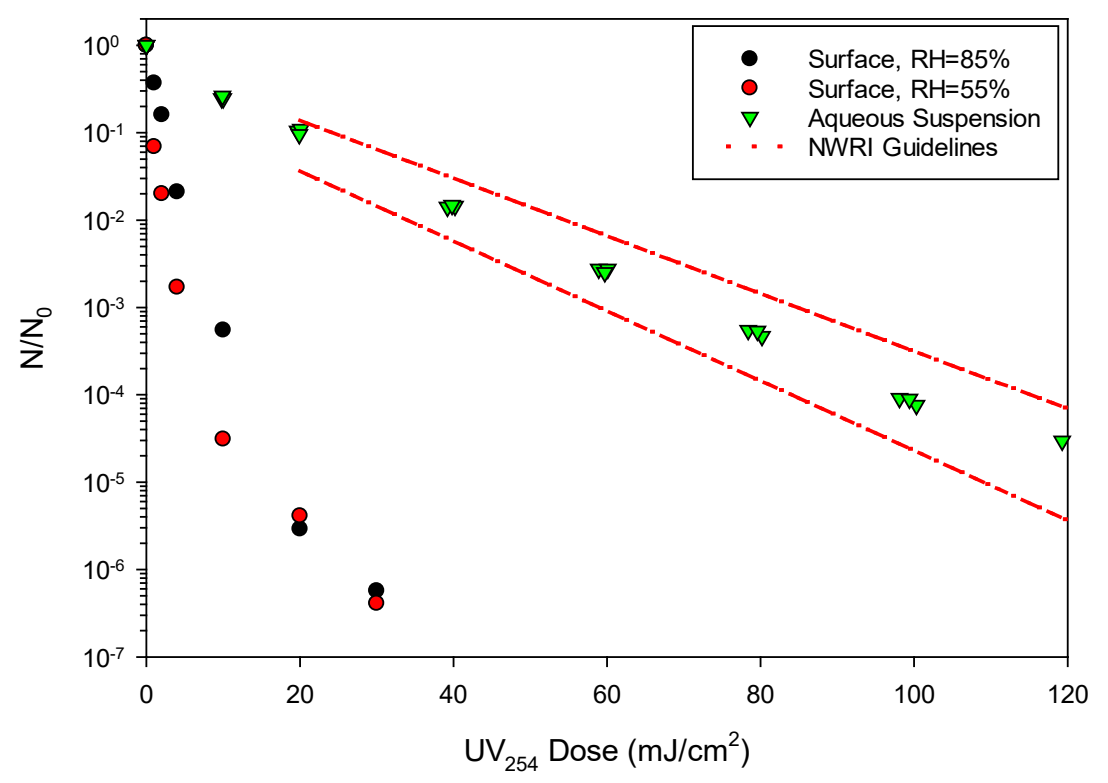

Fig. 3. $\mathrm{UV}_{254}$ dose-response behavior of coliphage MS2 on gel surfaces (at two different values of RH) and in aqueous suspension. Data for MS2 on surfaces are from Tseng and Li [32]. Data for MS2 in aqueous suspension were provided by HDR/HydroQual (O. Karl Scheible and Chengyue Shen, personal communication). Figure also shows guideline limits for MS2 UV 254 dose-response behavior, as suggested by the National Water Research Institute (NWRI) [41]. 


\section{Exposure to Solar UV-B Radiation}

Solar UV-B radiation is known to function as an effective disinfectant for inactivation of a wide range of microorganisms, including bacteria, viruses, and protozoa [42-44]. Inactivation of microbial and viral pathogens by exposure to solar UV-B radiation represents an important contributing factor in solar UV disinfection processes that are often used for production of drinking water in developing countries [45, 46].

A study conducted by scientists at the U.S. Department of Homeland Security indicated that UV-B radiation in ambient sunlight plays an important role in the environmental fate and stability of SARS-CoV2 [47]. Specifically, for solar irradiation at $40^{\circ} \mathrm{N}$ latitude, their measurements and modeling results indicated that $1 \log _{10}$ unit of inactivation would be achieved for SARS-CoV-2 suspended in saliva, after allowing for drying on the surface, when exposed to $6.8 \mathrm{~min}$ of midday sunlight on the summer solstice. By contrast, the same extent of inactivation would require $14.3 \mathrm{~min}$ of exposure at the winter solstice. For perspective, the 40th parallel (north) passes close to the U.S. cities of Philadelphia, PA, Columbus, OH, Indianapolis, IN, Boulder, $\mathrm{CO}$, and close to the California-Oregon border. Locations north of this line can expect to obtain slower inactivation by solar UV-B exposure, while those lying closer to the equator can expect to achieve more rapid inactivation by this mechanism.

Most commercial UV disinfection systems are developed around sources of UV-C radiation, rather than UV-B or UV-A radiation. This is largely because UV-C radiation is much more effective for inactivation of pathogens than either UV-B or UV-A radiation. Also, UV-C sources are inexpensive and relatively efficient at converting input electrical power into output UV-C radiation.

\section{Model Predictions of SARS-CoV-2 Sensitivity to UV254 Exposure}

Models have been developed to predict the sensitivity of viruses to UV irradiation, with particular emphasis given to solar UV-B exposure and $\mathrm{UV}_{254}$ radiation. Among the earliest of these efforts was the work of Lytle and Sagripanti, who developed a model to allow simulation of the sensitivity of a number of viruses that are pathogenic to humans and are of concern with respect to biodefense applications $[12,48$, 49]. Their model was based on the hypothesis that within a group of viruses, for which the structure of their genome is likely to be similar, the sensitivity of a virus to UV exposure is directly proportional to genome size. The model was applied for estimation of the sensitivity of viruses to solar UV-B exposure, as well as exposure to UV-C radiation at $\lambda=254 \mathrm{~nm}$. Their model provided estimates of viral inactivation responses that were judged by the authors to be acceptably close to measured values that had been reported in the literature. Using that approach, they were able to extend their model to estimate the sensitivity of SARSCoV-2 to $\mathrm{UV}_{254}$ exposure [13]. Their model predicted an inactivation rate constant for SARS-CoV-2 of $3.3 \mathrm{~cm}^{2} / \mathrm{mJ}$, based on an assumption of single-event (i.e., first-order) inactivation kinetics.

Pendyala et al. [14] developed the Pyrimidine Dinucleotide Frequency Value (PyNNFV) model based on the frequency of various dinucleotide sequences within the viral genome. Their model was shown to provide accurate estimates of viral sensitivity to $\mathrm{UV}_{254}$ exposure over a wide range of virus types. The PyNNFV model yielded an estimate of the rate constant for SARS-CoV-2 inactivation of $1.07 \mathrm{~cm}^{2} / \mathrm{mJ}$ at $254 \mathrm{~nm}$.

Rockey et al. [15] conducted a review of the literature related to $\mathrm{UV}_{254}$ dose-response behavior of viruses. For positive-sense, single-stranded RNA viruses, which include the coronaviruses, they developed a multiple linear regression model that yielded the lowest root-mean-squared relative prediction error (RMSrPE) based on the following variables: number of cytosines, uracils, uracil doublets, and uracil triplets. Their final model demonstrated RMSrPE that was lower than the error associated with measured values of inactivation constants from experiments. Their model indicated a $\mathrm{UV}_{254}$ inactivation constant of $(2.0 \pm 0.86) \mathrm{cm}^{2} / \mathrm{mJ}$ for SARS-CoV-2, and similar values for other coronaviruses that have been linked to serious human diseases, including SARS-CoV and MERS-CoV. 
Figure 4 illustrates the predictions of these three models, along with measured inactivation responses of SARS-CoV-2 at $254 \mathrm{~nm}$ in aqueous suspension. The models differ somewhat in their predictions of SARS-CoV-2 inactivation, but they all indicate that the virus is quite sensitive to $\mathrm{UV}_{254}$ irradiation. For perspective, the $\mathrm{UV}_{254}$ inactivation kinetics for SARS-CoV-2 inactivation predicted by these models were also similar to those that have been reported for many vegetative bacterial cells [50], which are generally considered to be easy to inactivate by UV-C irradiation. Coincidentally, the range of inactivation responses predicted by the three models is similar to the range of measured responses provided by the two reports of experimental SARS-CoV-2 inactivation by $\mathrm{UV}_{254}$ irradiation for aqueous suspensions of the virus [21, 22].

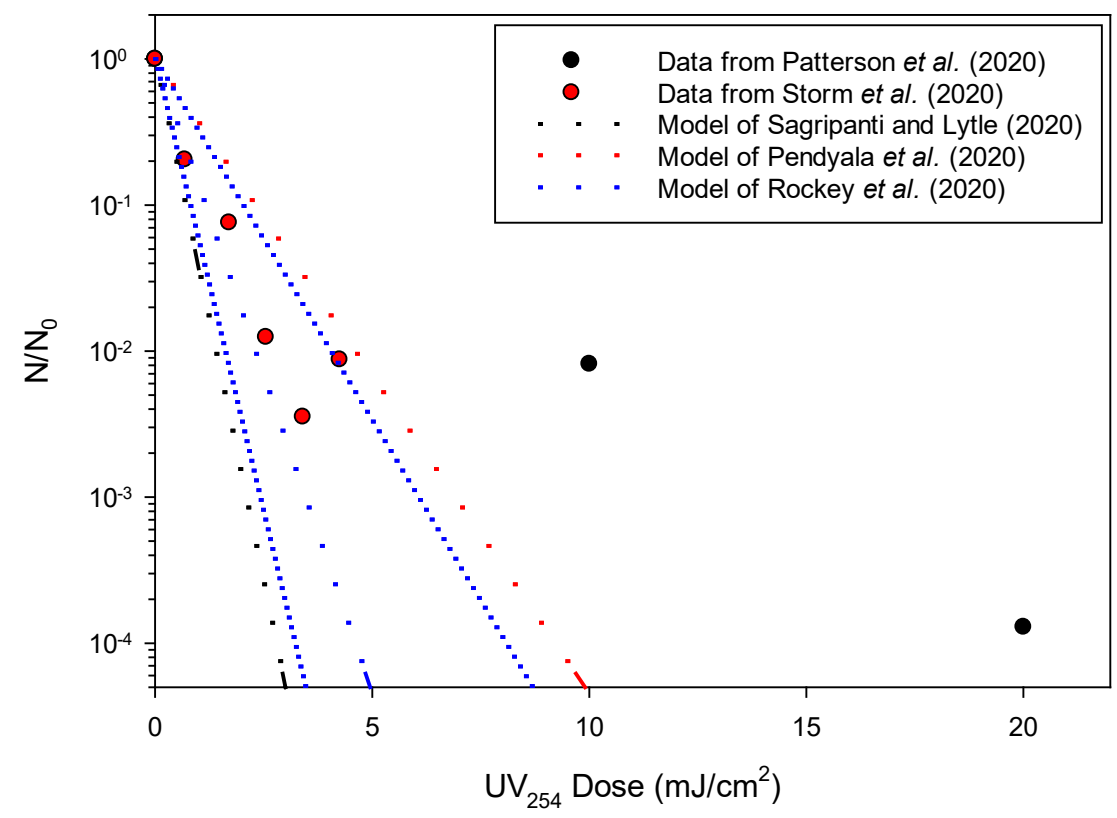

Fig. 4. Reported UV dose-response data for SARS-CoV-2 in aqueous suspension [21, 22] by exposure to UV 254 radiation and model predictions of SARS-CoV-2 inactivation by $\mathrm{UV}_{254}$ irradiation [13-15]. Dashed lines indicate mean first-order inactivation responses predicted by the models; dotted lines indicate the $95 \%$ margin of error for the model of Rockey et al. [15].

\section{Summary}

Available information indicates promise for the use of UV-C to inactivate SARS-CoV-2; however, it should be noted that some important details of the experiments reported to date have not been presented in the papers that have been published to describe SARS-CoV-2 inactivation by UV-C irradiation.

Specifically, it is important that experimental methods be implemented in a manner that allows absorption of incident UV radiation by the surrounding medium to be accounted for, explicitly. Likewise, it is important that radiation from the UV source be applied in a manner that allows accurate quantification of the applied fluence rate and dose [51]. It is likely that publications in this area will continue to emerge, and our collective understanding of the effectiveness of germicidal UV radiation for control of SARS-CoV-2 will grow. The effects of the medium of exposure, relative humidity, and wavelength(s) of exposure also need to be quantified.

Despite these shortcomings, available evidence suggests that UV-C radiation should be effective for inactivation of SARS-CoV-2. UV-C-based systems will have important roles in battling SARS-CoV-2 in air, on surfaces, and in other media. However, like all common disinfectants (e.g., UV, chlorine, ozone, hydrogen peroxide), a need exists to more clearly quantify the kinetics of inactivation for SARS-CoV-2 for these applications. 


\section{References}

[1] Rodriguez RA, Bounty S, Linden KG (2013) Long-range quantitative PCR for determining inactivation of adenovirus 2 by ultraviolet light. Journal of Applied Microbiology 114:1854-1865. https://doi.org/10.1111/jam.12169

[2] Beck SE, Hull NM, Poepping C, Linden KG (2018) Wavelength-dependent damage to adenoviral proteins across the germicidal UV spectrum. Environmental Science \& Technology 52:223-229. https://oi.org/10.1021/acs.est.7b04602

[3] Vazquez-Bravo B, Goncalves K, Shisler JL, Marinas BJ (2018) Adenovirus replication cycle disruption from exposure to polychromatic ultraviolet irradiation. Environmental Science \& Technology 52:3652-3659. https://doi.org/10.1021/acs.est.7b06082

[4] van Doremalen N, Bushmaker T, Morris DH, Holbrook MG, Gamble A, Williamson BN, Tamin A, Harcourt JL, Thornburg NJ, Gerber SI, Lloyd-Smith JO, de Wit E, Munster VJ (2020) Aerosol and surface stability of SARS-CoV-2 as compared with SARS-CoV-1. New England Journal of Medicine 382:1564-1567. https://doi.org/10.1056/NEJMc2004973

[5] MarshallWF III (2020) Can COVID-19 (Coronavirus) Spread Through Food, Water, Surfaces and Pets? (Mayo Clinic, Rochester, MN). Available at https://www.mayoclinic.org/diseases-conditions/coronavirus/expert-answers/can-coronavirusspread-food-water/faq-20485479

[6] WHO (2020) SARS (Severe Acute Respiratory Syndrome). (World Health Organization, Geneva Switzerland).

[7] Afshar ZM, Ebrahimpour S, Javanian M, Koppolu V, Vasigala VK, Hasanpour AH, Babazadeh A (2020) Coronavirus disease 2019 (COVID-19), MERS and SARS: Similarity and difference. Journal of Acute Disease 9:194-199.

[8] Ceccarelli M, Berretta M, Venanzi Rullo E, Nunnari G, Cacopardo B (2020) Editorial—Differences and similarities between severe acute respiratory syndrome (SARS)-coronaVirus (CoV) and SARS-CoV-2. Would a rose by another name smell as sweet? European Review for Medical and Pharmacological Sciences 24:2781-2783. https://doi.org/10.26355/eurrev_202003_20551

[9] Payne S (2017), Family Coronaviridae. Viruses: From Understanding to Investigation (Academic Press, San Diego, CA), pp $149-158$.

[10] Hadi J, Dunowska M, Wu SY, Brightwell G (2020) Control measures for SARS-CoV-2: A review on light-based inactivation of single-stranded RNA viruses. Pathogens 9(9):737. https://doi.org/10.3390/pathogens9090737

[11] Heßling M, Hönes K, Vatter P, Lingenfelder C (2020) Ultraviolet irradiation doses for coronavirus inactivation - Review and analysis of coronavirus photoinactivation studies (Ultraviolette Bestrahlungsdosen für die Inaktivierung von Coronaviren Review und Analyse von Coronavirusinaktivierungsstudien). GMS Hygiene and Infection Control 15:8. https://doi.org/10.3205/dgkh000343

[12] Lytle CD, Sagripanti JL (2005) Predicted inactivation of viruses of relevance to biodefense by solar radiation. Journal of Virology 79:14244-14252. https://doi.org/10.1128/JVI.79.22.14244-14252.2005

[13] Sagripanti JL, Lytle CD (2020) Estimated inactivation of coronaviruses by solar radiation with special reference to COVID-19. Photochemistry and Photobiology 96:731-737. https://doi.org/10.1111/php.13293

[14] Pendyala B, Patras A, Pokharel B, D'Souza D (2020) Genomic modeling as an approach to identify surrogates for use in experimental validation of SARS-CoV-2 and HuNoV inactivation by UV-C treatment. Frontiers in Microbiology 11:572331. https://doi.org/10.3389/fmicb.2020.572331

[15] Rockey NC, Henderson JB, Chin K, Raskin L, Wigginton KR (2020) Predictive modeling of virus inactivation by UV. bioRxiv. https://doi.org/10.1101/2020.10.27.355479

[16] Kariwa H, Fujii N, Takashima I (2004) Inactivation of SARS coronavirus by means of povidone-iodine, physical conditions, and chemical reagents. Japanese Journal of Veterinary Research 52:105-112. http://doi.org/10.14943/jjvr.52.3.105

[17] Duan SM, Zhao XS, Wen RF, Huang JJ, Pi GH, Zhang SX, Han J, Bi SL, Ruan L, Dong XP; SARS Research Team (2003) Stability of SARS coronavirus in human specimens and environment and its sensitivity to heating and UV irradiation. Biomedical and Environmental Sciences 16:246-255.

[18] Darnell MER, Subbarao K, Feinstone SM, Taylor DR (2004) Inactivation of the coronavirus that induces severe acute respiratory syndrome, SARS-CoV. Journal of Virological Methods 121:85-91. https://doi.org/10.1016/j.jviromet.2004.06.006

[19] Gerchman Y, Mamane H, Friedman N, Mandelboim M (2020) UV-LED disinfection of coronavirus: Wavelength effect. Journal of Photochemistry and Photobiology B-Biology 212:112044. https://doi.org/10.1016/j.jphotobiol.2020.112044

[20] Heilingloh CS, Aufderhorst UW, Schipper L, Dittmer U, Witzke O, Yang D, Zheng X, Sutter K, Trilling M, Alt M, Steinmann E, Krawczyk A (2020) Susceptibility of SARS-CoV-2 to UV irradiation. American Journal of Infection Control 48:1273-1275. https://doi.org/10.1016/j.ajic.2020.07.031

[21] Patterson EI, Prince T, Anderson ER, Casas-Sanchez A, Smith SL, Cansado-Utrilla C, Solomon T, Griffiths MJ, Acosta-Serrano Á, Turtle L, Hughes GL (2020) Methods of inactivation of SARS-CoV-2 for downstream biological assays. The Journal of Infectious Diseases 222: 1462-1467. https://doi.org/10.1093/infdis/jiaa507

[22] Storm N, McKay LGA, Downs SN, Johnson RI, Birru D, de Samber M, Willaert W, Cennini G, Griffiths A (2020) Rapid and complete inactivation of SARS-CoV-2 by ultraviolet-C irradiation. Scientific Reports 10:22421. https://doi.org/10.1038/s41598020-79600-8

[23] Inagaki H, Saito A, Sugiyama H, Okabayashi T, Fujimoto S (2020) Rapid inactivation of SARS-CoV-2 with deep-UV LED irradiation. Emerging Microbes \& Infections 9:1744-1747. https://doi.org/10.1080/22221751.2020.1796529 
[24] Kitagawa H,Nomura T, Nazmul T, Omori K, Shigemoto N, Sakaguchi T, Ohge H (2020) Effectiveness of 222-nm ultraviolet light on disinfecting SARS-CoV-2 surface contamination. American Journal of Infection Control. https://doi.org/10.1016/j.ajic.2020.08.022

[25] Beck SE, Wright HB, Hargy TM, Larason TC, Linden KG (2015) Action spectra for validation of pathogen disinfection in medium-pressure ultraviolet (UV) systems. Water Research 70:27-37. https://doi.org/10.1016/j.watres.2014.11.028

[26] Rauth AM (1965) Physical state of viral nucleic acid and sensitivity of viruses to ultraviolet light. Biophysical Journal 5:257273. https://doi.org/10.1016/s0006-3495(65)86715-7

[27] Mamane-Gravetz H, Linden KG, Cabaj A, Sommer R (2005) Spectral sensitivity of Bacillus subtilis spores and MS2 coliphage for validation testing of ultraviolet reactors for water disinfection. Environmental Science \& Technology 39:7845-7852. https://doi.org/10.1021/es048446t

[28] Woo MH,Grippin A, Anwar D, Smith T, Wu C-Y, Wander JD (2012) Effects of relative humidity and spraying medium on UV decontamination of filters loaded with viral aerosols. Applied and Environmental Microbiology 78:5781-5787. https://doi.org/10.1128/AEM.00465-12

[29] Peccia J, Werth HM, Miller S, Hernandez M (2001) Effects of relative humidity on the ultraviolet induced inactivation of airborne bacteria. Aerosol Science and Technology 35:728-740. https://doi.org/10.1080/02786820152546770

[30] Fletcher LA (2004) The influence of relative humidity on the UV susceptibility of airborne gram negative bacteria. IUVA News (International Ultraviolet Association, Bethesda, MD), pp 12-19.

[31] Ko G, First MW, Burge HA (2000) Influence of relative humidity on particle size and UV sensitivity of Serratia marcescens and Mycobacterium bovis BCG aerosols. Tubercle and Lung Disease 80:217-228. https://doi.org/10.1054/tuld.2000.0249

[32] Tseng CC, Li CS (2007) Inactivation of viruses on surfaces by ultraviolet germicidal irradiation. Journal of Occupational and Environmental Hygiene 4:400-405. https://doi.org/10.1080/15459620701329012

[33] McDevitt JJ, Lai KM, Rudnick SN, Houseman EA, First MW, Milton DK. (2007) Characterization of UVC light sensitivity of vaccinia virus. Applied and Environmental Microbiology 73:5760-5766. https://doi.org/10.1128/AEM.00110-07

[34] McDevitt JJ, Rudnick SN, Radonovich LJ (2012) Aerosol susceptibility of influenza virus to UV-C light. Applied and Environmental Microbiology 78:1666-1669. https://doi.org/10.1128/AEM.06960-11

[35] Otter JA, Donskey C, Yezli S, Douthwaite S, Goldenberg SD, Weber DJ(2016) Transmission of SARS and MERS coronaviruses and influenza virus in healthcare settings: The possible role of dry surface contamination. Journal of Hospital Infection 92:235250. https://doi.org/10.1016/j.jhin.2015.08.027

[36] Ahlawat A, Wiedensohler A, Mishra SK (2020) An overview on the role of relative humidity in airborne transmission of SARSCoV-2 in indoor environments. Aerosol and Air Quality Research 20:1856-1861. https://doi.org/10.4209/aaqr.2020.06.0302

[37] Biryukov J, Boydston JA, Dunning RA, Yeager JJ, Wood S, Reese AL, Ferris A, Miller D, Weaver W, Zeitouni NE, Phillips A, Freeburger D, Hooper I, Ratnesar-Shumate S, Yolitz J, Krause M, Williams G, Dawson DG, Herzog A, Dabisch P, Wahl V, Hevey MC, Altamura LA (2020) Increasing temperature and relative humidity accelerates inactivation of SARS-CoV-2 on surfaces. Msphere 5(4):e00441-20. https://doi.org/10.1128/mSphere.00441-20

[38] Yao MS, Zhang L, Ma JX, Zhou L (2020) On airborne transmission and control of SARS-Cov-2. Science of the Total Environment 731:139178. https://doi.org/10.1016/j.scitotenv.2020.139178

[39] Casanova LM, Jeon S, Rutala WA, Weber DJ, Sobsey MD (2010) Effects of air temperature and relative humidity on coronavirus survival on surfaces. Applied and Environmental Microbiology 76:2712-2717. https://doi.org/10.1128/AEM.02291-09

[40] Rahman MA, Hossain MG, Singha AC, Islam MS, Islam MA (2020) A retrospective analysis of influence of environmental/air temperature and relative humidity on SARS-CoV-2 outbreak. Journal of Pure and Applied Microbiology 14:1705-1714. https://doi.org/10.22207/JPAM.14.3.09

[41] Emerick RW, Tchobanoglous G (2012) Ultraviolet Disinfection Guidelines for Drinking Water and Water Reuse (National Water Research Institute, Fountain Valley, CA).

[42] Busse MM, Becker M, Applegate BM, Camp JW, Blatchley ER (2019) Responses of Salmonella typhimurium LT2, Vibrio harveyi, and Cryptosporidium parvum to UVB and UVA radiation. Chemical Engineering Journal 371:647-656. https://doi.org/10.1016/j.cej.2019.04.105

[43] Mbonimpa EG, Vadheim B, Blatchley ER (2012) Continuous-flow solar UVB disinfection reactor for drinking water. Water Research 46:2344-2354. https://doi.org/10.1016/j.watres.2012.02.003

[44] Mbonimpa EG, Blatchley ER, Applegate B, Harper WF (2018) Ultraviolet A and B wavelength-dependent inactivation of viruses and bacteria in the water. Journal of Water and Health 16:796-806. https://doi.org/10.2166/wh.2018.071

[45] Zhang Y, Sivakumar M, Yang SQ, Enever K, Ramezanianpour M (2018) Application of solar energy in water treatment processes: A review. Desalination 428:116-145. https://doi.org/10.1016/j.desal.2017.11.020

[46] Nelson KL, Boehm AB, Davies-Colley RJ, Dodd MC, Kohn T, Linden KG, Liu Y, Maraccini PA, McNeill K, Mitch WA, Nguyen TH, Parker KM, Rodriguez RA, Sassoubre LM, Silverman AI, Wigginton KR, Zepp RG (2018) Sunlight-mediated inactivation of health-relevant microorganisms in water: A review of mechanisms and modeling approaches. Environmental Science-Processes \& Impacts 20:1089-1122. https://doi.org/10.1039/c8em00047f

[47] Ratnesar-Shumate S, Williams G, Green B, Krause M, Holland B, Wood S, Bohannon J, Boydston J, Freeburger D, Hooper I, Beck K, Yeager J, Altamura LA, Biryukov J, Yolitz J, Schuit M, Wahl V, Hevey M, Dabisch P (2020) Simulated sunlight rapidly inactivates SARS-CoV-2 on surfaces. Journal of Infectious Diseases 222:214-222. https://doi.org/10.1093/infdis/jiaa274

[48] Sagripanti JL, Lytle CD (2007) Inactivation of influenza virus by solar radiation. Photochemistry and Photobiology 83:12781282. https://doi.org/10.1111/j.1751-1097.2007.00177.x 
[49] Sagripanti JL, Lytle CD (2011) Sensitivity to ultraviolet radiation of Lassa, vaccinia, and Ebola viruses dried on surfaces. Archives of Virology 156:489-494. https://doi.org/10.1007/s00705-010-0847-1

[50] Malayeri AH, Mohseni M, Cairns B, Bolton JR, (2016) Fluence (UV dose) required to achieve incremental log inactivation of bacteria, protozoa, viruses and algae. IUVA News 18(3):4-6. Available at https://uvsolutionsmag.com/stories/pdf/archives/180301_UVSensitivityReview_full.pdf

[51] Bolton JR, Linden KG (2003) Standardization of methods for fluence (UV dose) determination in bench-scale UV experiments. Journal of Environmental Engineering 129:209-215. https://doi.org/10.1061/(ASCE)0733-9372(2003)129:3(209)

About the authors: Ernest R. Blatchley III is the Lee A. Rieth Professor in Environmental Engineering at Purdue University, where he holds a joint faculty appointment in the Lyles School of Civil Engineering and the Division of Environmental \& Ecological Engineering. Professor Blatchley conducts research related to physico/chemical processes of environmental engineering, with particular focus on theory and applications of UV radiation.

Brian Petri is research director at Trojan Technologies, a manufacturer of UV-based disinfection systems for water, wastewater, and industrial water treatment. Dr. Petri holds a Ph.D. in biology from York University, and master's and bachelor's degrees in chemical engineering from the University of Toronto. His research focuses on reactor design and performance testing and measuring UV doseresponses for viruses and other microorganisms.

Wenjun Sun is an associate professor at the School of Environment, Tsinghua University. Dr. Sun holds a Ph.D. in environmental engineering from Tsinghua University, and bachelor's degrees in water supply and drainage engineering from Tongji University. His research focuses on UV disinfection, UV LED application on water treatment, UV advanced oxidation processes, and risk assessment for drinking water.

The National Institute of Standards and Technology is an agency of the U.S. Department of Commerce. 